\title{
Effect of Synthesis Temperature on the Composition of Electro- lytic Iron Phosphide
}

\author{
Hokon Kim and Heon-Cheol Shin* \\ School of Materials Science and Engineering, Pusan National University, Busan 609-735, Republic of Korea
}

\begin{abstract}
In this study, we investigated the composition of an electrolytic Fe phosphide at different synthesis temperatures. We found that the ratio of $\mathrm{Fe}$ in the electrodeposit increases with synthesis temperature, whereas the oxygen content introduced into the electrodeposit by the atmospheric oxidation of Fe decreases. The aim of this study was to identify the reason for this effect. For this purpose, the ratio of $\mathrm{Fe}$ and $\mathrm{P}$ in the electrodeposits prepared at different temperatures was analyzed in depth. In addition, the types and ratios of $\mathrm{Fe}$ phosphide phases were considered. It was proved that with increase in temperature, a significant amount of Fe reacted with $\mathrm{P}$ to form Fe phosphide phases, and consequently, the amount of residual pure $\mathrm{Fe}$ that would react directly with oxygen decreased.
\end{abstract}

Keywords : Fe phosphide, Electrodeposition, Temperature, Composition

Received : 9 January 2018, Accepted : 16 March 2018

\section{Introduction}

Metal phosphides are functional materials used in a broad range of applications, including high-energydensity supercapacitors and lithium battery electrodes [1-3], low-cost, high-efficiency catalysts [4], high-efficiency solar cell electrodes [5], radiation detectors [6], and wear-resistant thin films [7]. Metal phosphides are fabricated by a variety of methods. For instance, they are produced in the powder form by ball milling [8] and solid- and liquid-phase syntheses $[9,10]$, and in the thin-film form by chemical vapor deposition [11] and phosphorization [12]. These methods, however, present different challenges. Ball milling is problematic because it requires a long time for completion of the synthesis and causes particle cohesion. Solid-phase synthesis is not useful for producing large quantities of high-purity compounds. In contrast, liquid-phase synthesis has the advantage of producing high-purity powder; however, it is expensive and involves various time-

*E-mail address: hcshin@pusan.ac.kr

DOI: https://doi.org/10.5229/JECST.2018.9.1.78 consuming complex processes. Besides, the chemical vapor deposition method, which is used to produce thin films, requires expensive equipment and elaborate infrastructure, and it is not useful for large-area synthesis. Consequently, finding an efficient and reliable method to produce metal phosphides remains a key research topic.

Electrolytic plating is an economical method for thin film synthesis, which can be performed using relatively simple equipment such as electrochemical cells and a current/voltage source. Moreover, the amount of electrodeposit formed on the substrate and its composition, purity, and structure can be easily controlled by adjusting the applied current or voltage, temperature, or electrolyte composition [13], which allows for large-area synthesis. However, using electrolytic plating to synthesize a specific metal phosphide remains a challenging task mainly because of the complicated deposition mechanism. There has been limited research regarding the changes in the characteristics of metal phosphide electrodeposits depending on the electrolytic plating conditions (e.g., electrolyte $\mathrm{pH}[14])$. The present study examined the composition of an electrolytic Fe phosphide at differ- 
ent synthesis temperatures. The elemental composition of the electrodeposits is first presented, and the abnormal change in oxygen content with respect to iron is put forth as a question. To understand such compositional variation, the Fe-only phase and phosphide phase were quantitatively analyzed separately.

\section{Experimental}

The plating solution contained $0.72 \mathrm{M} \mathrm{FeSO}_{4} \cdot 7 \mathrm{H}_{2} \mathrm{O}$ (Junsei Chemical Co. Ltd., Japan), $0.36 \mathrm{M} \mathrm{NaH}_{2}$ $\mathrm{PO}_{2} \cdot \mathrm{H}_{2} \mathrm{O}$ (Junsei Chemical Co. Ltd., Japan), $0.11 \mathrm{M}$ $\mathrm{H}_{2} \mathrm{NCH}_{2} \mathrm{COOH}$ (Junsei Chemical Co. Ltd., Japan), and $5 \mathrm{mM} \mathrm{H}_{2} \mathrm{C}_{2} \mathrm{O}_{4}$ (Sigma-Aldrich, U.S.). $\mathrm{H}_{2} \mathrm{SO}_{4}$ (Duksan Pure Chemicals Co. Ltd., Korea) was added to the solution to maintain the $\mathrm{pH}$ at 2.3. A highpurity copper foil (99.8\%) (Alfa Aesar, U.K.), pretreated with dilute $\mathrm{H}_{2} \mathrm{SO}_{4}$ and washed with distilled water (to remove the native oxide layer), was used as the substrate. The exposed area was $0.25 \mathrm{~cm}^{2}$. A three-electrode electrochemical cell was constructed using a platinum wire and a saturated calomel electrode (SCE), which were used as the counter and reference electrodes, respectively. To synthesize the $\mathrm{Fe}$ phosphide thin film, a constant voltage of $-1.7 \mathrm{~V} v \mathrm{~s}$. SCE was applied for $10 \mathrm{~s}$ within the temperature range of $10-70^{\circ} \mathrm{C}$ using an IviumStat instrument (Ivium Technologies B.V., The Netherlands). The electrolyte was stirred to eliminate the evolved hydrogen gas, which would otherwise be adsorbed on the surface of the electrodes during synthesis.

The surface morphologies of the samples were observed using a field-emission scanning electron microscope (MIRA3; TESCAN, Czech Republic), and the crystal structure was analyzed using an X-ray diffractometer (Ultima-IV; Rigaku, Japan). An energy-dispersive X-ray spectrometer (APOLLO X; AMETEK, U.S.) and an X-ray photoelectron spectroscope (XPS) (Quantera SXM; ULVAC-PHI, Inc., Japan) were used to analyze the composition of the sample surface and to obtain a compositional depth profile, respectively.

\section{Results and Discussion}

Fig. 1 presents the surface morphology of the electrolytic Fe phosphide thin films synthesized at different temperatures. All the samples showed a uniform morphology, making it difficult to distinguish between them. The cracks on the surface neither changed with temperature, nor appeared in repeated experiments, implying that crack formation occurred during the handling process after plating. At all the studied temperatures, the samples were characterized as amorphous materials without long-range ordering, as shown in Fig. 2.

Fig. 3 shows the results of the surface composition analysis of the samples electroplated at $10-70^{\circ} \mathrm{C}$. The compositions indicated in the figure represent the average values from three spots randomly selected on the electrodeposits. Iron, phosphorus, copper (used as the substrate), and oxygen were detected. Electrolytic Fe phosphide is known to form through the following mechanism [14]:

$$
\begin{aligned}
& \mathrm{H}_{2} \mathrm{PO}_{2}^{-}+5 \mathrm{H}^{+}+4 \mathrm{e}^{-} \rightarrow \mathrm{PH}_{3}+2 \mathrm{H}_{2} \mathrm{O} \\
& 2 \mathrm{PH}_{3}+3 \mathrm{Fe}^{2+} \rightarrow 3 \mathrm{Fe}+2 \mathrm{P}+6 \mathrm{H}^{+} \\
& \mathrm{Fe}^{2+}+2 \mathrm{e}^{-} \rightarrow \mathrm{Fe}
\end{aligned}
$$

Fe and $\mathrm{P}$, the major components of the electrodeposit, are plated at a uniform ratio of 3:2 (Eqs. (1) and (2)), and additional plating involving only the $\mathrm{Fe}$ phase takes place simultaneously (Eq. (3)). Considering the deposition mechanism, it is noted in Fig. 3 that with increase in temperature, the Fe content increases, whereas the $\mathrm{P}$ content decreases. These results indicate that the increase in plating rate due to temperature is greater for Fe plating (Eq. (3)) than for Fe-P mixed plating (Eqs. (1) and (2)), i.e., the activation energy, which is a measure of the temperature sensitivity of the reaction, might be higher in the former case. On the other hand, a significant amount of $\mathrm{Cu}$, which is used as the substrate, is found only at low temperatures $\left(10^{\circ} \mathrm{C}\right)$. This might be because the electrodeposit is very thin at low temperatures, at which plating is relatively slow. For instance, the thickness of the $10^{\circ} \mathrm{C}$-sample $(<300 \mathrm{~nm})$ is much smaller than that of the $25^{\circ} \mathrm{C}$-sample $(>400 \mathrm{~nm})$ and $70^{\circ} \mathrm{C}$-sample $(>700 \mathrm{~nm})$, as presented in the insets in Fig. 1.

The presence of oxygen in the deposits is particularly noteworthy in Fig. 3 because oxygen is not involved in any part of the deposition reactions shown in Eqns. (1)-(3). To the best of our knowledge, there are no reports on the oxidation of Fe phosphide and the incomplete reduction of hypophosphite in the 

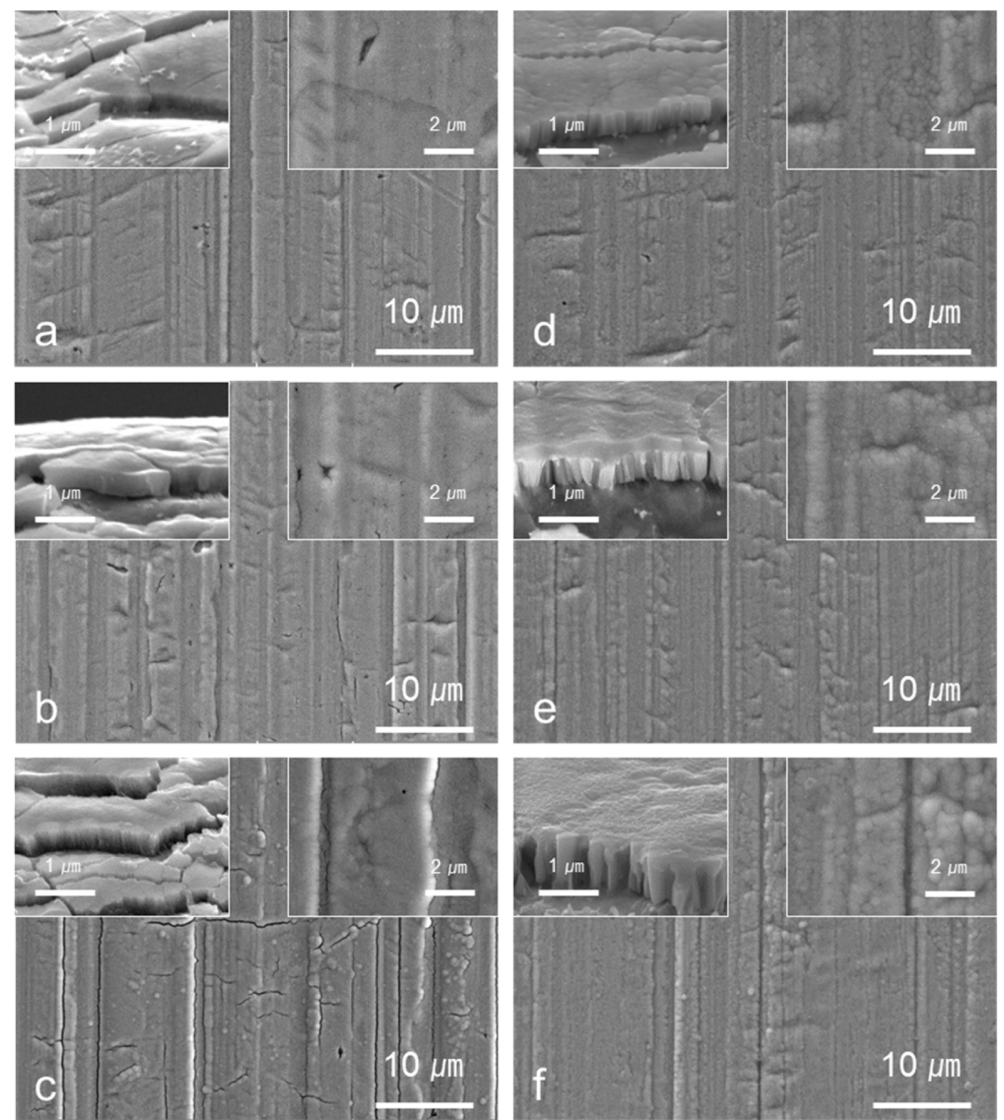

Fig. 1. Surface views of samples electrodeposited at (a) 10, (b) 25, (c) 40, (d) 50, (e) 60, and (f) $70^{\circ} \mathrm{C}$. The insets are the inclined view (left) and magnified surface view (right).

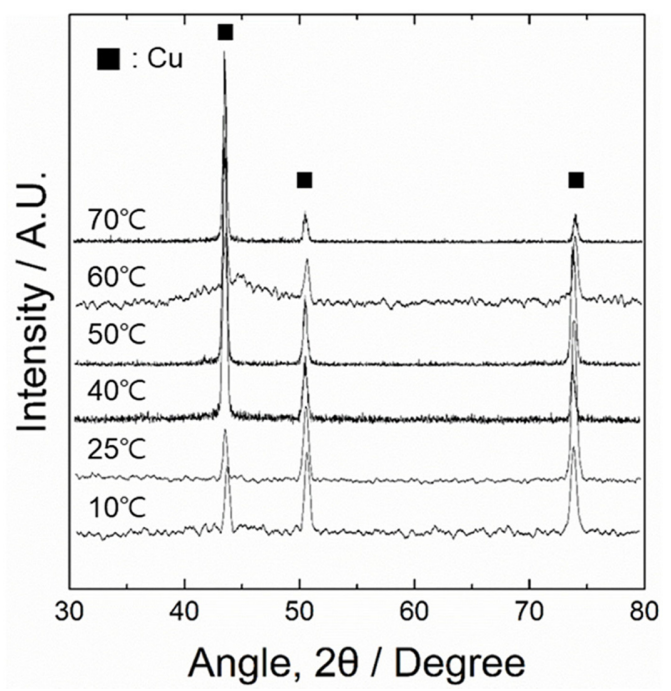

Fig. 2. X-ray diffraction patterns of the samples electrodeposited at different temperatures. electrolyte for incorporation into the electrodeposits. Instead, considering that $\mathrm{Fe}$ has a far greater tendency to be oxidized as compared with $\mathrm{P}[15,16]$, the presence of oxygen in the deposits may be attributed to atmospheric oxidation of Fe. Oxygen has frequently been detected in electroplated metals due to atmospheric oxidation [17]. Considering the mechanism by which oxygen is introduced into the deposit, the amount of oxygen must critically depend on the amount of Fe. More precisely, the amount of oxygen increases proportionately with the amount of $\mathrm{Fe}$ available to react with it. Unexpectedly, composition analysis (Fig. 3) shows an increase in the Fe ratio and a decrease in the oxygen ratio in the electrodeposit as the synthesis temperature is raised. This indicates that the Fe content in the deposit increases, while the actual amount of Fe available for reaction with oxygen decreases. The above arguments strongly suggest that with increase in synthesis temperature, the 
amount of Fe plated according to Eq. (3) increases; however, a greater percentage of the plated $\mathrm{Fe}$ is

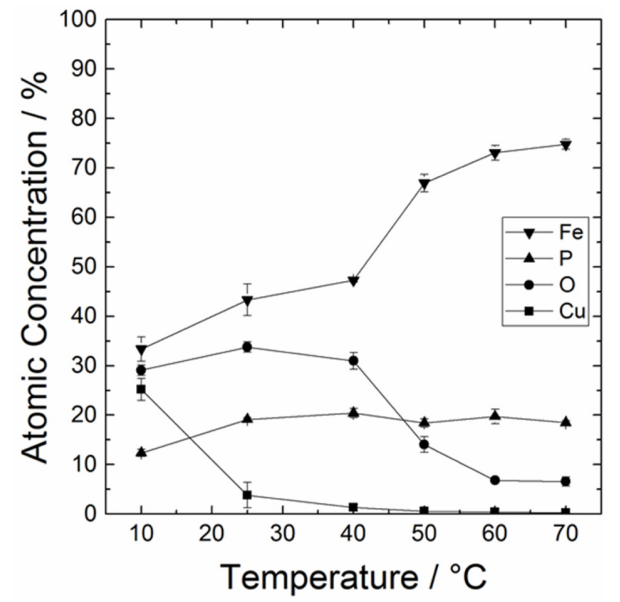

Fig. 3. Atomic concentration on the surface of samples electrodeposited at different temperatures analyzed by energy dispersive X-ray spectrometry. involved in the formation of Fe phosphide. Consequently, the amount of pure $\mathrm{Fe}$ available for reaction with oxygen decreases.

To experimentally verify this claim, the concentrations and phases of two samples prepared at different temperatures $\left(25\right.$ and $\left.50^{\circ} \mathrm{C}\right)$ were thoroughly analyzed. Fig. 4(a) presents the compositional depth profile of the electrodeposit synthesized at $25^{\circ} \mathrm{C}$. Except for the early stage of plating (to a depth of $c a$. $\geq 300 \mathrm{~nm}$ ), an even distribution of $\mathrm{Fe}$ and $\mathrm{P}$ could be seen regardless of the thickness, which is consistent with the results reported in literature [14]. Besides, the average $\mathrm{Fe} / \mathrm{P}$ ratio was about 78:22. Fig. 4(b) shows the $\mathrm{O} 1 \mathrm{~s} \mathrm{X}$-ray photoelectron spectra used to analyze the binding form of oxygen. Based on deconvolution of the peaks, it was determined that oxygen is present as $\mathrm{Fe}_{2} \mathrm{O}_{3}(530.2 \mathrm{eV}$ [18]) and $\mathrm{FeOOH}$ (531.5 eV [19]). Fig. 4(c) shows the Fe 2p X-ray photoelectron spectra used to determine the form of $\mathrm{Fe}$ in the deposit. It was confirmed that $\mathrm{Fe}$ is present as $\mathrm{Fe}_{2} \mathrm{P}$ (706.6 eV [20]), $\mathrm{FeP}$ (707.2 eV [21]), $\mathrm{FeOOH}$
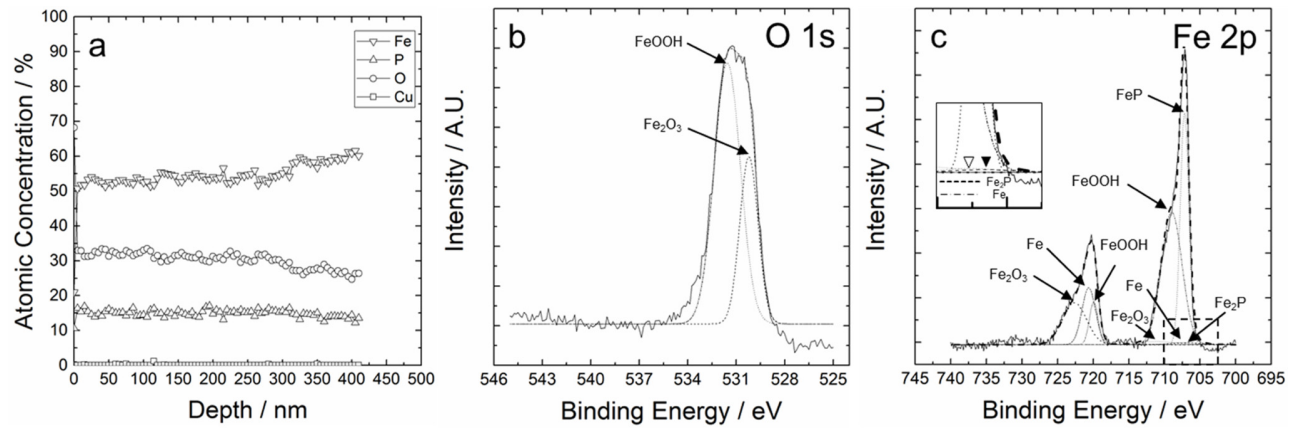

Fig. 4. (a) Compositional depth profiles of the sample electrodeposited at $25^{\circ} \mathrm{C}$. (b) and (c) are its $\mathrm{O} 1 \mathrm{~s}$ and $\mathrm{Fe} 2 \mathrm{p}$ XPS spectra.

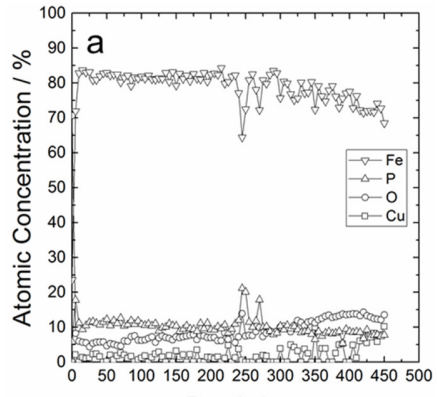

Depth / nm
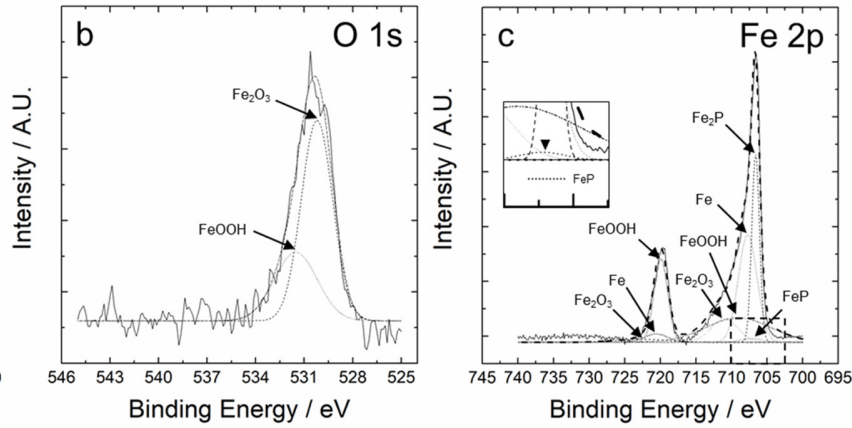

Fig. 5. (a) Compositional depth profiles of the sample electrodeposited at $50^{\circ} \mathrm{C}$. (b) and (c) are its $\mathrm{O}$ 1s and Fe $2 p$ XPS spectra. 
(709.0 eV [22] and $719.9 \mathrm{eV}$ [23]), $\mathrm{Fe}(707.7 \mathrm{eV}$ [24] and $720.6 \mathrm{eV}$ [25]), and $\mathrm{Fe}_{2} \mathrm{O}_{3}(711.0 \mathrm{eV}[23]$ and $722.6 \mathrm{eV}[26])$. In order to improve the reliability of the XPS analyses, all the binding energies of $\mathrm{Fe}$ oxides and Fe phosphides in the literature were considered when deconvoluting the spectra. The ratio of the corresponding peak areas (the ratio of each phase) was approximately $1: 28: 44: 11: 16$. Based on this, the Fe:P ratio was calculated to be $80: 20$, which agreed well with the average Fe:P ratio (78:22) estimated from Fig. 4(a).

Fig. 5(a) shows the compositional depth profile of the sample prepared at $50^{\circ} \mathrm{C}$. There is a distinct increase in the $\mathrm{Fe}$ ratio as compared to that in the $25^{\circ} \mathrm{C}$-sample. Fe and $\mathrm{P}$ are relatively evenly distributed (average Fe:P ratio of approximately $88: 12$ ) with the only exception at a depth of $\geq 300 \mathrm{~nm}$, similar to the case of the $25^{\circ} \mathrm{C}$-sample. Fig. 5 (b) confirms that oxygen is bonded to $\mathrm{Fe}$ in the form of $\mathrm{Fe}_{2} \mathrm{O}_{3}$ (530.2 eV [18]) and FeOOH (531.5 eV [19]). Moreover, as shown in Fig. 5(c), Fe is present in the form of $\mathrm{Fe}_{2} \mathrm{P}(706.6 \mathrm{eV}$ [20]), $\mathrm{FeP}$ (707.2 eV [21]), $\mathrm{FeOOH}$ (709.0 eV [22] and $719.9 \mathrm{eV}$ [23]), $\mathrm{Fe}(707.7 \mathrm{eV}$ [24] and $720.6 \mathrm{eV}$ [25]), and $\mathrm{Fe}_{2} \mathrm{O}_{3}(711.0 \mathrm{eV}$ [23], 722.6 $\mathrm{eV}$ [26]). The ratio of each peak area is 20:1:38:30:11. Accordingly, the Fe:P ratio was calculated to be 86:14, consistent with the average Fe:P ratio of 88:12 (Fig. 5(a)). On the other hand, no evidence was found in the XPS spectra regarding the presence of incomplete reduction products of hypophosphite (e.g., $\mathrm{H}_{\mathrm{x}} \mathrm{PO}_{\mathrm{y}}$ ). This strongly indicates that oxygen in the film mainly originates from the atmospheric oxidation of $\mathrm{Fe}$ after the electrolytic deposition.

In summary, the electrodeposit synthesized at higher temperatures showed a higher percentage of $\mathrm{Fe}(78 \%$ at $25^{\circ} \mathrm{C}$ and $88 \%$ at $50^{\circ} \mathrm{C}$ ), most of which was present in the form of Fe phosphides. More precisely, Fe present as $\mathrm{Fe}$ phosphides (mainly $\mathrm{FeP}$ ) in the $25^{\circ} \mathrm{C}$-sample was about $30 \%$, whereas $\mathrm{Fe}$ present as $\mathrm{Fe}$ phosphides (mainly $\mathrm{Fe}_{2} \mathrm{P}$ ) in the $50^{\circ} \mathrm{C}$-sample was approximately $41 \%$. Accordingly, the amount of $\mathrm{Fe}$ available for reaction with oxygen, i.e., the Fe-only phase, decreased with increasing synthesis temperature.

\section{Conclusions}

In this work, it was demonstrated that the proportion of the phases (Fe-only and $\mathrm{Fe}$ phosphides) in an electrolytic Fe phosphide thin film significantly depends on the synthesis temperature. Because the $\mathrm{Fe}$ and Fe phosphide contents and the type of Fe-phosphide phase in the film directly affect its functionality, close attention should be paid to the synthesis temperature in order to obtain a particular thin film composition, and thus, the desired functionality. Electrolytic Fe phosphides with different Fe:P ratios prepared at various temperatures are being tested as electrode materials for functional electrochemical devices, and the results will be reported in a separate paper.

\section{Acknowledgement}

This research was supported by the National Research Foundation of Korea Grants funded by the Korea Government (NRF-2017R1D1A3B04031667). One of the authors (H. Kim) was supported by scholarship for graduate students in science and engineering funded by the Hyundai Motor Chung Mong-Koo Foundation (CMKF-S-012).

\section{References}

[1] Y. Lu, J.K. Liu, X.Y. Liu, S. Huang, T.Q. Wang, X.L. Wang, C.D. Gu, J.P. Tu, S.X. Mao, CrystEngComm., 2013, 15(35), 7071-7079.

[2] K. Aso, A. Hayashi, M. Tatsumisago, Inorg. Chem., 2011, 50(21), 10820-10824.

[3] J. Yang, Y. Zhang, C. Sun, H. Liu, L. Li, W. Si, W. Huang, Q. Yan, X. Dong, Nano Res., 2016, 9(3), 612621.

[4] H. Yang, Y. Zhang, F. Hu, Q. Wang, Nano Lett., 2015, 15(11), 7616-7620.

[5] Y. Y. Dou, G. R. Li, J. Song and X. P. Gao, Phys. Chem. Chem. Phys., 2012, 14(4), 1339-1342.

[6] F. Dubecky, P. Bohacek, B. Zatko, M. Sekacova, J. Huran, V. Smatko, R. Fornari, E. Gombia, R. Mosca, P.G. Pelfer, Nucl. Instrum. Methods Phys. Res., Sect. A, 2004, 531(1), 181-191.

[7] M. Palaniappa, S.K. Seshadri, Wear, 2008, 265(5), 735740.

[8] W. Li, H. Li, Z. Lu, L. Gan, L. Ke, T. Zhai, H. Zhou, Energy Environ. Sci., 2015, 8(12), 3629-3636.

[9] H. Pfeiffer, F. Tancret, T. Brousse, Electrochim. Acta, 2005, 50(24), 4763-4770.

[10] K. Yan, Y. Li, X. Zhang, X. Yang, N. Zhang, J. Zheng, B. Chen, K. J. Smith, Int. J. Hydrogen Energy, 2015, 40(46), 16137-16146.

[11] A. P. Leitner, D. E. Schipper, J. H. Chen, A. C. Colson, I. Rusakova, B. K. Rai, E. Morosan, K. H. Whitmire, Chem. Eur. J., 2017, 23(23), 5565-5572. 
[12] T. R. Hellstern, J. D. Benck, J. Kibsgaard, C. Hahn, T. F. Jaramillo, Adv. Energy Mater, 2016, 6, 1501758.

[13] M. D. Hossain, C. M. Mustafa, M. M. Islam, J. Electrochem. Sci. Technol., 2017, 8(3), 197-205.

[14] I. T. Park, H. C. Shin, Electrochem. Commun., 2013, 33, 102-106.

[15] S. Baken, P. Salaets, N. Desmet, P. Seuntjens, E. Vanlierde, E. Smolders, Environ. Sci. Technol., 2015, 49(5), 28862894.

[16] T. D. Mayer, W. M. Jarrell, Wat. Res., 2000, 34(16), 3949-3956.

[17] S. J. Hearne, J. A. Floro, J. Appl. Phys., 2005, 97(1), 014901.

[18] W. Temesghen, P. Sherwood, Anal. Bioanal. Chem., 2002, 373(7), 601-608.

[19] H. Liu, D. Xu, A. Q. Dao, G. Zhang, Y. Lv, H. Liu, Corros. Sci., 2015, 101, 84-93.

[20] Y. Wang, L. Zhang, H. Li, Y. Wang, L. Jiao, H. Yuan, L.
Chen, H. Tang, X. Yang, J. Power Sources, 2014, 253, 360-365.

[21] J. Kibsgaard, C. Tsai, K. Chan, J. D. Benck, J. K. Nørskov, F. Abild-Pedersen, T. F. Jaramillo, Energy Environ. Sci., 2015, 8(10), 3022-3029.

[22] M. J. Carmezim, A. M. Simoes, M. F. Montemor, M. D. C. Belo, Corros. Sci., 2005, 47(3), 581-591.

[23] F. G. Ferris, K. Tazaki, W. S. Fyfe, Chem. Geol., 1989, 74(3-4), 321-330.

[24] R. S. Dutta, G. K. Dey, A. Lobo, R. Purandare, S. K. Kulkarni, Metall. Mater. Trans. A, 2002, 33(5), 14371447.

[25] N. Luo, T. Chen, K. Liu, Y. Shen, Mendeleev Commun., 2013, 23(3), 153-154.

[26] V. Balouria, A. Kumar, S. Samanta, A. Singh, A. K. Debnath, A. Mahajan, R. K. Bedi, D. K. Aswal, S. K. Gupta, Sens. Actuators, B, 2013, 181, 471-478. 